\title{
The historical evolution of the regulations for the Florence Nightingale $\mathrm{Medal}^{\dagger}$
}

Review article

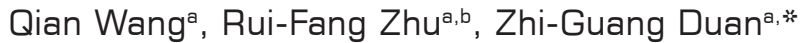

aSchool of Nursing, Shanxi Medical University, Taiyuan, Shanxi 030001, China

${ }^{b}$ First Hospital of Shanxi Medical University, Taiyuan, Shanxi 030001, China

Received: 20 October 2017; Accepted: 20 November 2017; Published: 20 March 2018

\begin{abstract}
Objective: This study aimed to explore the 100-year changes in regulations for the Florence Nightingale Medal.
Methods: We used the announcements of the Florence Nightingale Medal awards as the research object to analyze - via historical and inductive methods - the regulations for receiving the Florence Nightingale Medal.

Results: In the award years, the greatest number of winners per award year was 71 and the lowest was 12 . The medal was initially exclusively awarded to living people but evolved to include both living and deceased people. The recipients were balanced among all countries. The gender of the winners showed a changing trend from being limited to only females to including both males and females. There was also a shift from emphasis on only dedication of the recipient to equal emphasis on both dedication and innovation. Conclusions: The selection criteria for recipients of the Florence Nightingale Medal evolved from consideration of those showing only dedication to equal consideration of both dedication and innovation.
\end{abstract}

Keywords: Florence Nightingale Medal • Florence Nightingale Medal awards • dedication • innovation • evolution • regulations (C) Shanxi Medical Periodical Press.

\section{Introduction}

The Florence Nightingale Medal is the highest honor awarded to nurses who have made an outstanding contribution to the nursing profession. The Medal was established by the International Committee of the Red Cross at the 8th International Conference of the Red Cross in 1907. The Florence Nightingale Medal was 1st awarded in1920. Subsequently, it was awarded in odd years. As of 2015, there have been a total of 45 award periods covering an award period of 100 years. Its regulations have also been revised

\footnotetext{
${ }^{\dagger}$ This project was supported by the Special Fund of Key Discipline Construction (the characteristic subject of Nursing course) of Shanxi Province in China.
}

several times. This study uses historical methods to analyze the Florence Nightingale Medal awards and assess its changing track of regulations to explore nursing developments accompanying the Florence Nightingale Medal.

\section{Objectives and methods}

\subsection{Introduction to the Florence Nightingale Medal awards}

The Florence Nightingale Medal award is always announced on May 12 of the awarding years. The logo of the Red Cross appears on the upper left corner, and the upper right corner contains the circular number. The award includes 3 parts: the 1st part includes the title 


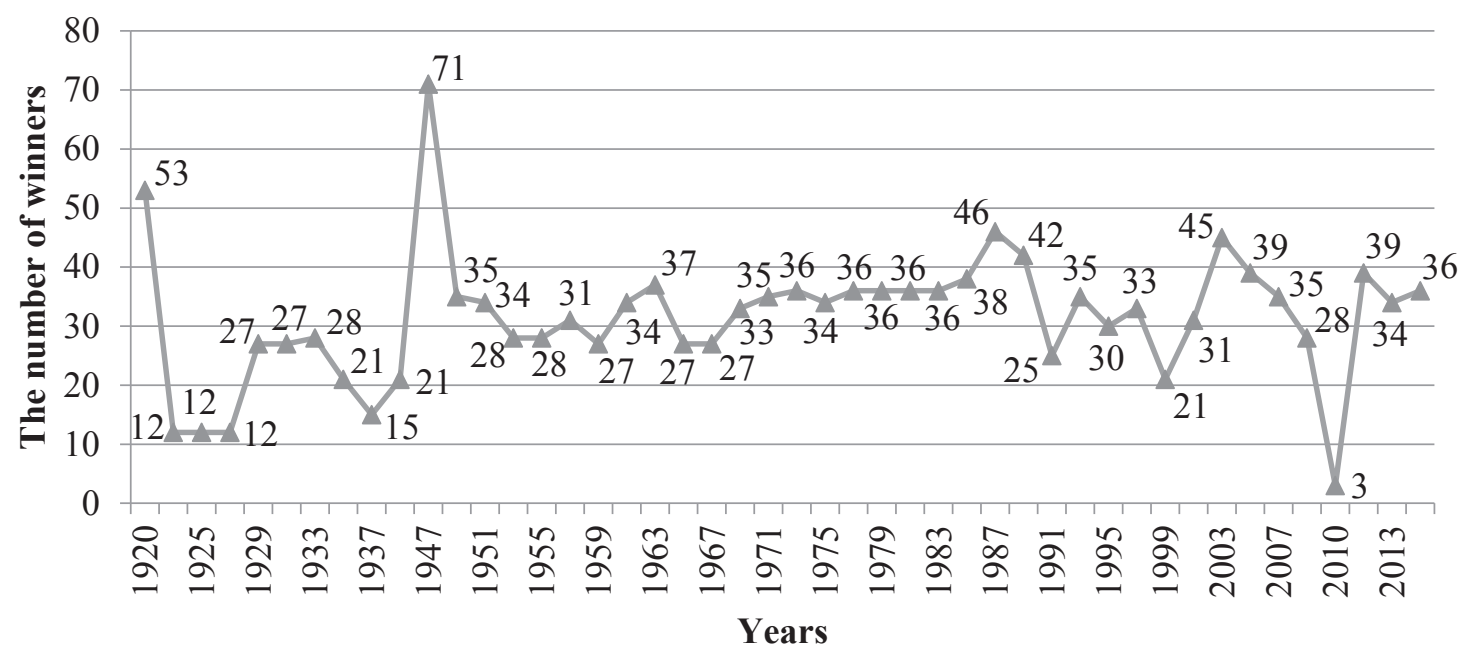

Figure 1. The number of recipients of successive Florence Nightingale Medals.

and date in a fixed format of " $x$ award of the Florence Nightingale Medal" followed by "Geneva, May 12, xxxx (year)". The 2nd part is the main body of the award, which typically includes 2 sections: the preface and winner information. The 3rd part includes the requirements and signature. Each country is required to perform a ceremony celebrating the solemnity of the winner's character. The president of the International Committee of the Red Cross signs the award. From the beginning of September of the year preceding the year in which the Medal is awarded, the International Committee of the Red Cross invites the Central Committees of the National Societies by means of a circular and application forms. The names of the candidates that they consider to be qualified to be awarded a Medal must reach the International Committee of the Red Cross before March 1 of the year on which the Medal is to be awarded.

\subsection{Study objects and methods}

This study uses the original awards of the Florence Nightingale Medal (1920-2015) provided by the International Committee of the Red Cross as study objects and applies historical methods to assess the awards to investigate the evolution of the partial clauses of the regulations.

\section{Findings}

\subsection{Number of recipients of the Florence Nightingale Medal}

It was proposed in the 1st award of the Florence Nightingale Medal that the number of medals awarded should be $<50$ every time and awards will be granted in odd years. As shown in Figure 1, the maximum number of medals awarded is 71 and the minimum is 12 for each previous award year, while 3 medals were awarded in a non-award year. There are 2 award ceremonies in which medals were awarded to $>50$ winners. They are the 1st award ceremony of 1920 and the 11th ceremony of 1947 . The only non-award year in which 3 winners were awarded is 2010 .

The awards announcement for the 1st award ceremony in 1920 referred to 41 people, which did not exceed the maximum limit of 50 people. However, in the final count of recipients, the number was 53 . A possible reason for this increase involved a controversy surrounding whether the International Committee of the Red Cross can grant the award to deceased individuals, and also, many countries did not recommend deceased individuals for the 1st award. However, for the 2nd award in 1923, deceased individuals were granted the award (Figure 1).

This information helps to deduce that the International Committee of the Red Cross has offered supplemental awards to 12 deceased individuals after the 1st award announcement was published.

The 11th award of the Florence Nightingale Medal included 71 recipients in 1947 because the Medal was not awarded over 3 award periods during World War II (1941, 1943, and 1945). After the war, awarding of the Medal resumed in 1947 and was granted to 71 nurses. This number of recipients did not exceed the total number that should be granted for 3 periods.

The International Committee of the Red Cross awarded the Medal to 3 Haitian nurses ${ }^{1}$ in 2010 for the exceptional courage that they demonstrated in helping victims of the earthquake that struck on January 12 , 2010 , and for their many years of selfless work towards sick and wounded people.

Given the increasing number of countries that applied, the regulations have been revised several 
times, and it was ultimately determined at the 1991 meeting in Budapest that the maximum number of awards should be 50 .

\subsection{Can the award be given posthumously?}

In 1920, the 1st award announcement stipulated that the Medal cannot be applied for deceased individuals for 2 reasons. First, the regulations stipulated that medals must be personally awarded by their state leaders or the Chairman of the Central Committee of the Red Cross, and the International Committee of the Red Cross considered that the founder of this Medal focused on living nurses. Second, the International Committee of the Red Cross did not require all countries to include sacrificial nurses among the recommended persons in the lists before the 1st award.

At the 1991 delegates meeting in Budapest, the current regulations of the Florence Nightingale Medal were passed, which stipulated that "The Medal may be awarded posthumously if the prospective recipient has fallen during active service." When did this change begin? We found some clues in the preface of the announcement for the 1st award of the Florence Nightingale Medal, indicating that "As the arbiter of the regulations, the International Committee of the Red Cross can add an additional condition if they considered that it was suitable."

That is, the Medal can be posthumously awarded as an additional condition. When did the changes occur? The analysis concluded that the number of winners can be deduced given that the International Committee of the Red Cross had reached an agreement and had awarded a supplemental award before the 2nd award was given.

\subsection{Quota allocation of the prize}

The 4th award of the Florence Nightingale Medal in 1927 made the following statement: "Based on the principles of justice and equity, the International Committee of the Red Cross decided that if the Red Cross never awarded the Medal and its recommended candidates met the prescribed conditions, these individuals would likely be awarded the Medal. The 15th Interna- tional Conference of the Red Cross hoped to minimize the Medal number to maintain the honor of the prize. The International Committee of the Red Cross typically only assigned a quota for each country. If a candidate failed to be selected this year, he or she could be recommended again during the next awards ceremony" (the 4th award of the Florence Nightingale Medal). This statement reflected the principle of equilibrium of countries when selecting candidates.

\subsection{The gender of the recipients}

Before the time of Florence Nightingale, nurses were mostly low-status women or nuns. Ms. Nightingale's services led to the development of modern nursing. However, the profession predominantly involved females, and few men were nurses. The profession was associated with the low status of nursing at that time as well as patriarchy. ${ }^{2}$ At the 1991 delegates meeting in Budapest, the International Committee of the Red Cross 1st passed the regulation that male nurses could be considered as candidates. In 1993, the award announcement mentioned that "the object of this Medal is to honor male and female nurses and voluntary aides who have distinguished themselves, whether in time of peace or in war, by their exceptional devotion to the wounded, the sick, the disabled or persons whose health is at risk." Since then, male nurses have been given attention and have been promoted in the nursing profession. Figure 2 shows that the $1 \mathrm{st}$ male recipient was granted the Medal in 1993, and an increasing trend followed.

\subsection{The contributions of the recipients}

Given that the Florence Nightingale Medal was 1st awarded immediately after the World War I, the International Committee gave priority to nurses who made outstanding contributions during the war when selected. The 3rd award of the Florence Nightingale Medal in 1925 posted as follows: "Faced with (In the face of) the excellent candidates presented, the International Committee hoped to distribute as many awards as possible, but the seats were limited. The International Committee

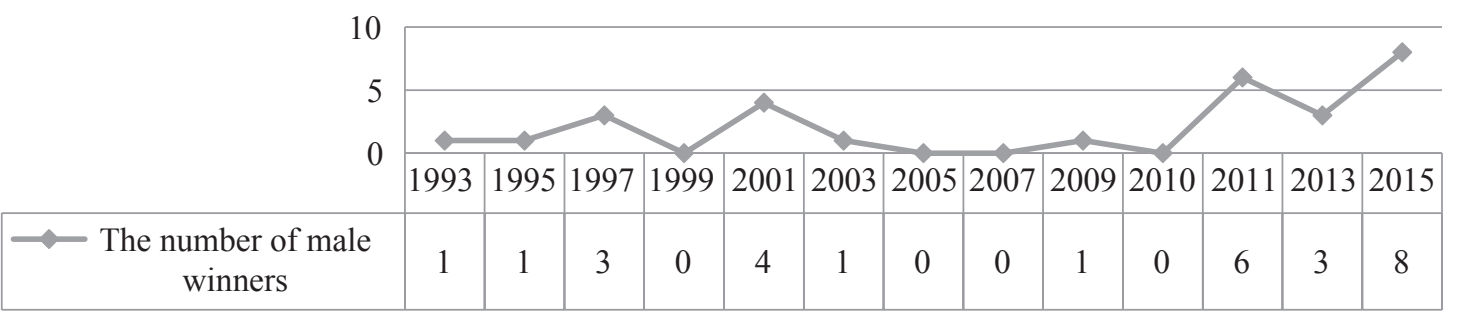

Figure 2. The number of male recipients of the Florence Nightingale Medal. 
had to eliminate some candidates and select nurses who played a role in times of war. The International Committee considered that the last war was still quite recent and needed to consider this factor when selecting recipients. Contributions made in times of war or public disasters were given a higher priority than contributions to nursing work in hospitals and schools".

The following was mentioned in the award of 1949 , "As limited by the regulations, which provide for the awarding of a maximum of 36 medals each 2 years, the International Committee had to make a difficult choice among the excellent candidates presented. The basic principle was to measure the selfless devotion spirit of nurses and voluntary aids. If they had equal qualifications, priority was given to the candidates who had more years of work experience" (The 12th award of the Florence Nightingale Medal).

The above award showed that the selection criteria of the Medal placed an emphasis on the dedication of the winners, and this emphasis was continued until the end of the 20th century.

The award announcement of 2003, for the 1st time, referred to initiative in its objective. "The objective of this Medal is to honor male and female nurses and voluntary aides who have distinguished themselves by exceptional courage and devotion to the victims of a conflict or disaster, by exemplary service or by a creative and pioneering spirit in the areas of public health or nursing education" (The 39th award of the Florence Nightingale Medal).

Thus, the selection regulations of the Florence Nightingale Medal started to pay attention to initiative but lacked quantitative standards.

\section{Conclusions}

\subsection{The regulations of the Florence Nightingale Medal reflected the neutrality of the International Committee of the Red Cross}

The Florence Nightingale Medal is the highest medal and honor in the international nursing field. The historical evolution of the selection regulations of the Medal indicate that the International Committee of the Red Cross is a neutral reconciliatory institution, as reflected by the solemnity and holiness of the Florence Nightingale Medal. The committee ensured that the award was balanced for each country when formulating its regulations.

\section{2 "Humanitarianism, love, and dedication" encompass the spirit of the International Red Cross and serve as the basis for the selection criteria of the Florence Nightingale Medal based on dedication}

The Florence Nightingale Medal was established by the International Red Cross, so the selection criteria were inevitably influenced by its founding institution. The 1st award of the Medal was awarded during World War I and subsequently World War II broke out. During these 2 wars, the main social background of the selection criteria placed an emphasis on dedication based on wartime services and working years.

\subsection{The selection criteria of the Florence Nightingale Medal changed from an emphasis on dedication to equal attention to dedication and innovation}

For the 2003 award, the selection criteria of the Medal already began to be representative of the initiative of the recipients. As the war ended and world peace was established, the International Red Cross stayed current with the times and was committed to reform and innovation. The International Red Cross allowed male nurses to be awarded with the Medal and complied with the trend of the times. The emphasis on dedication was changed to equal attention for both dedication and innovation, confirming the conclusion of the study on China's recipients. ${ }^{3,4}$ The future development of nursing and embodiment of the nursing occupational spirit require not only dedication but also innovation. The continuous revisions of the regulations with the times ensure their guidance of the direction of nursing.

\section{Conflicts of interest}

All contributing authors declare no conflicts of interest.

\section{Acknowledgments}

The authors thank the International Red Cross for providing the original materials of the award announcements. The contents of the award referred to in this paper were based on a translation of the original award announcements. Because many languages were used in the original materials, please provide corrections on inaccurate translation. 


\section{References}

1. ICRC. Florence Nightingale Medal. http://www.icrc. org/chi/resources/documents/misc/5qmkdb.htm. 2003.

3. Duan ZG. Dedication and creation: the education value orientation of the Nightingale Prize laureates. Chin J Med Educ. 2009;29:1-4. (in Chinese).

2. Andrist LC, Nicholas PK, Wolf KA. A History of Nursing Ideas. Canada: Jones and Bartlett Publishers; 2006:35-42.

4. Duan ZG, Wang Q, Chen H. Innovation: Florence Nightingale's spirit is important as dedication. Chin Nurs Res. 2007;1:1-2. (in Chinese).

How to cite this article: Wang Q, Zhu RF, Duan ZG. The historical evolution of the regulations for the Florence Nightingale Medal. Frontiers Nurs. 2018; 1: 01-06. https://doi.org/10.1515/fon-2018-0005 